\section{Use of fecal immunochemical testing in patients presenting in primary care with lower GI symptoms}

I read with interest the CMAJ article "The appropriate use of fecal immunochemical testing"1 (FIT).

I agree with most of the points made and firmly support the view that there is no evidence that fecal occult blood testing (FOBT) and FIT are of any value in assessment of inpatients in secondary care, ${ }^{2,3}$ particularly in acute admissions. ${ }^{4}$

However, I would argue strongly that the newer FIT (but not the traditional FOBT) are very useful in assessing the many patients who present in primary care with lower gastrointestinal symptoms.

Substantial evidence has accumulated over the last decade that a low fecal hemoglobin concentration is reassuring in symptomatic patients, as many studies show a very high negative predictive value for significant bowel disease (colorectal cancer, advanced adenoma and inflammatory bowel disease).5,6 Moreover, a very high fecal hemoglobin concentration should lead to urgent referral. In Scotland, quantitative FIT is used and results reported as "not detected" if < $10 \mu \mathrm{g} \mathrm{Hb} / \mathrm{g}$ feces, numerically if between 10 and $400 \mu \mathrm{gHb} / \mathrm{g}$ feces and $>400 \mu \mathrm{g} \mathrm{Hb} / \mathrm{g}$ feces if above the upper measurement limit of the FIT system used. ${ }^{7}$ Fecal immunochemical testing has been widely introduced as a routine investigation available to general practitioners throughout the United Kingdom and is facilitating the referral for colonoscopy for those patients who would most benefit.

No diagnostic test is perfect, however, and a few cases of clinically important bowel disease will have a "negative" FIT result. The FIT result should not be interpreted in isolation, and relevant clinical indications for referral should be heeded. Further, for some patients with a negative FIT result, safety-netting strategies - in which people at low risk, but not no risk, of having cancer are actively monitored in primary care to see if the risk of cancer changes $^{8}-$ may be required. ${ }^{9}$

Thus, although controversies remain, ${ }^{10}$ the use of FIT in assessment of patients with symptoms in primary care is considered well worth investigating in countries with limited colonoscopy capacity.

\section{Callum G. Fraser PhD}

Senior research fellow, Centre for Research into Cancer Prevention and Screening, University of Dundee, Ninewells Hospital and Medical School, Dundee, Scotland

- Cite as: CMAJ 2020 April 6;192:E377. doi: 10.1503/cmaj.74717

\section{References}

1. Forbes N, Hilsden RJ, Heitman SJ. The appropriate use of fecal immunochemical testing. CMAJ 2020;192:E68.

2. Fraser CG. A future for faecal haemoglobin measurements in the medical laboratory. Ann Clin Biochem 2012;49:518-26.
3. Narula N, Ulic D, Al-Dabbagh R, et al. Fecal occult blood testing as a diagnostic test in symptomatic patients is not useful: a retrospective chart review. Can J Gastroenterol Hepatol 2014;28:421-6.

4. Drescher MJ, Stapleton S, Britstone Z, Fried J, Smally AJ. A call for a reconsideration of the use of fecal occult blood testing in emergency medicine. J Emerg Med 2020 Jan. 8 [Epub ahead of print]. doi: 10.1016/j.jemermed.2019.09.026.

5. Westwood M, Lang S, Armstrong N, et al. Faecal immunochemical tests (FIT) can help to rule out colorectal cancer in patients presenting in primary care with lower abdominal symptoms: a systematic review conducted to inform new NICE DG30 diagnostic guidance. BMC Med 2017;15:189.

6. Quantitative faecal immunochemical tests to guide referral for colorectal cancer in primary care [Diagnostics guidance [DG30]]. London: National Institute for Health and Care Excellence (NICE); July 2017. Available: www.nice.org.uk/ guidance/dg30 (accessed 2020 Jan. 21).

7. Mowat C, Digby J, Strachan JA, et al. Impact of introducing a faecal immunochemical test (FIT) for haemoglobin into primary care on the outcome of patients with new bowel symptoms: a prospective cohort study. BMJ Open Gastroenterol 2019;6:e000293.

8. Early diagnosis of cancer how do we make sure patients don't slip through the net? Oxford: Cancer Research UK; 2016. Available: www. cancerresearchuk.org/sites/default/files/safety _netting_england_201607.pdf (accessed 2020 Jan. 23).

9. Godber IM, Benton SC, Fraser CG. Setting up a service for a faecal immunochemical test for haemoglobin (FIT): a review of considerations, challenges and constraints. J Clin Pathol 2018;71:1041-5.

10. Fraser CG. Faecal immunochemical tests for haemoglobin (FIT) in the assessment of patients with lower abdominal symptoms: current controversies. Gastroenterol Hepatol 2019;42:263-70.

Competing interests: Callum Fraser acts as a paid consultant to Hitachi Chemical Diagnostic Systems Co., Ltd., Tokyo, Japan, and has accepted support to attend relevant conferences from Alpha Labs Ltd, Eastleigh, Hants, UK. 